Research paper

\title{
Decreased salivary lactoferrin levels are specific to Alzheimer's disease
}

\author{
Marta González-Sánchez ${ }^{\mathrm{a}, \mathrm{b}}$, Fernando Bartolome ${ }^{\mathrm{a}, *}$, Desiree Antequera ${ }^{\mathrm{a}}$, \\ Veronica Puertas-Martín , Pilar González ${ }^{\mathrm{c}}$, Adolfo Gómez-Grande ${ }^{\mathrm{d}}$, Sara Llamas-Velasco ${ }^{\mathrm{a}, \mathrm{b}}$, \\ Alejandro Herrero-San Martín ${ }^{\mathrm{a}, \mathrm{b}}$, David Pérez-Martínez $z^{\mathrm{a}, \mathrm{b}}$, Alberto Villarejo-Galende ${ }^{\mathrm{a}, \mathrm{b}}$, \\ Mercedes Atienza ${ }^{\mathrm{e}}$, Miriam Palomar-Bonet ${ }^{\mathrm{e}}$, Jose Luis Cantero ${ }^{\mathrm{e}}$, George Perry ${ }^{\mathrm{f}}$, Gorka Orive ${ }^{\mathrm{g}}$, \\ Borja Ibañez ${ }^{\mathrm{h}}$, Hector Bueno ${ }^{\mathrm{i}}$, Valentin Fuster ${ }^{\mathrm{j}}$, Eva Carro ${ }^{\mathrm{a}, *}$ \footnotetext{
Octubre Research Institute (imas12), 28041 Madrid, Spain

Neurology Service Hospital Universitario 12 de Octubre, Madrid, Spain

' Centro Nacional de Investigaciones Cardiovasculares Carlos III (CNIC), Madrid, Spain; CIBER de Enfermedades Cardiovasculares, Madrid, Spain; Hospital Universitario 12 de Octubre Research Institute (imas12), Madrid, Spain

${ }^{\mathrm{d}}$ Nuclear Medicine Service, Hospital Universitario 12 de Octubre, Madrid, Spain; Hospital Universitario 12 de Octubre Research Institute (imas12), 28041 Madrid, Spain

e Laboratory of Functional Neuroscience, Pablo de Olavide University, Seville, Spain, CIBERNED, Network Center for Biomedical Research in Neurodegenerative Diseases, Spain

${ }^{\mathrm{f}}$ Department of Biology and Neurosciences Institute, University of Texas at San Antonio, San Antonio, TX, USA

${ }^{g}$ Laboratory of Pharmacy and Pharmaceutical Technology, Faculty of Pharmacy, University of the Basque Country, Vitoria, Spain; Networked Center for Biomedical

${ }^{\mathrm{h}}$ Centro Nacional de Investigaciones Cardiovasculares Carlos III (CNIC), Madrid, Spain, CIBER de Enfermedades Cardiovasculares, Madrid, Spain; IIS-Fundacion Jiménez Díaz Hospital, Madrid, Spain

i Centro Nacional de Investigaciones Cardiovasculares Carlos III (CNIC), Madrid, Spain, CIBER de Enfermedades Cardiovasculares, Madrid, Spain; Facultad de Medicina, Universidad Complutense de Madrid, Madrid, Spain; Hospital Universitario 12 de Octubre Research Institute (imas12), Cardiology Department, Hospital Universitario 12 de Octubre, Madrid, Spain
} \\ Network Center for Biomedical Research in Neurodegenerative Diseases (CIBERNED), Spain; Group of Neurodegenerative Diseases, Hospital Universitario 12 de \\ Research in Bioengineering, Biomaterials and Nanomedicine (CIBER-BBN), Spain \\ ${ }^{j}$ Centro Nacional de Investigaciones Cardiovasculares Carlos III (CNIC), Madrid, Spain; Icahn School of Medicine at Mount Sinai, New York, New York, United States
}

\section{A R T I C L E I N F O}

\section{Article History:}

Received 16 April 2020

Revised 15 May 2020

Accepted 29 May 2020

Available online 22 June 2020

\section{Keywords:}

Alzheimer's disease

Lactoferrin

Saliva

Pet imaging

Biomarkers

Frontotemporal dementia

\begin{abstract}
A B S T R A C T
Background: Evidences of infectious pathogens in Alzheimer's disease (AD) brains may suggest a deteriorated innate immune system in AD pathophysiology. We previously demonstrated reduced salivary lactoferrin (Lf) levels, one of the major antimicrobial proteins, in AD patients.

Methods: To assess the clinical utility of salivary Lf for AD diagnosis, we examine the relationship between salivary Lf and cerebral amyloid- $\beta(\mathrm{A} \beta)$ load using amyloid-Positron-Emission Tomography (PET) neuroimaging, in two different cross-sectional cohorts including patients with different neurodegenerative disorders. Findings: The diagnostic performance of salivary Lf in the cohort 1 had an area under the curve [AUC] of $0 \bullet 95$ $(0 \bullet 911-0 \bullet 992)$ for the differentiation of the prodromal $\mathrm{AD} / \mathrm{AD}$ group positive for amyloid-PET $\left(\mathrm{PET}^{+}\right)$versus healthy group, and $0 \bullet 97(0 \bullet 924-1)$ versus the frontotemporal dementia (FTD) group. In the cohort 2 , salivary Lf had also an excellent diagnostic performance in the health control group versus prodromal AD compari-

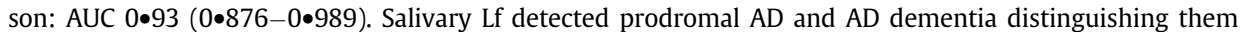
from FTD with over $87 \%$ sensitivity and $91 \%$ specificity.

Interpretation: Salivary Lf seems to have a very good diagnostic performance to detect AD. Our findings support the possible utility of salivary $\mathrm{Lf}$ as a new non-invasive and cost-effective AD biomarker.

Funding: Instituto de Salud Carlos III (FIS15/00780, FIS18/00118), FEDER, Comunidad de Madrid (S2017/BMD3700; NEUROMETAB-CM), and CIBERNED (PI2016/01) to E.C.; Spanish Ministry of Economy and Competitiveness (SAF2017-85310-R) to J.L.C., and (PSI2017-85311-P) to M.A.; International Centre on ageing CENIE-POCTEP (0348_CIE_6_E) to M.A.; Instituto de Salud Carlos III (PIE16/00021, PI17/01799), to H.B.
\end{abstract}

(c) 2020 The Authors. Published by Elsevier B.V. This is an open access article under the CC BY-NC-ND license. (http://creativecommons.org/licenses/by-nc-nd/4.0/)

\footnotetext{
* Corresponding authors.

E-mail addresses: fbartolome.imas12@h12o.es (F. Bartolome), carroeva@h12o.es (E. Carro).
} 


\section{Research in context}

\section{Evidence before this study}

We searched PubMed for articles published in English up to March 2020 with the terms "Alzheimer's biomarkers", "peripheral biomarkers", "saliva proteins", "saliva function", "preclinical Alzheimer", "Alzheimer prediction", "lactoferrin", "infections", "immune system", among others. All these studies conclude the urgent need for the development of early diagnostic methods that can accurately detect and diagnose Alzheimer's disease $(A D)$. In recent years, there have been intensified efforts in the search for minimum or non-invasive peripheral markers, such as blood, or saliva, for the early diagnosis of AD. Findings have shown the association between $\mathrm{AD}$ and immune system, including virus, bacteria and yeast infections, which is associated with an increased inflammatory response. Moreover, it has been proposed that brain infections may be involved in the development of AD. The dissemination of oral microorganisms to the brain is controlled by antimicrobial peptides, as part of the innate immune system. In the last decade, several studies have explored the role of these antimicrobial peptides as potential biomarkers for AD. In 2017, we showed that salivary lactoferrin (Lf) discriminates between patients with mild cognitive impairment (MCI) and AD from control subjects.

\section{Added value of this study}

This is, to our knowledge, the first study to assess the excellent diagnostic performance and specificity of a saliva-based single biomarker to detect prodromal $\mathrm{AD}$ and $\mathrm{AD}$ dementia based on their amyloid-PET biomarker profile. Moreover, an independent cross-sectional independent study was able to replicate the diagnostic performance of saliva Lf concentrations. The results shown that salivary Lf levels are decreased in AD and are associated with amyloid-PET imaging profile even in prodromal disease. The fact that salivary Lf levels are unchanged in other degenerative dementia, such as frontotemporal dementia (FTD), supports the possible use of salivary Lf in the differential diagnosis of $A D$ vs other dementias.

\section{Implications of all the available evidence}

The most clinically relevant finding of this study is the excellent diagnostic performance of salivary Lf to detect prodromal AD and $\mathrm{AD}$ dementia distinguishing from other dementia as FTD, with sensitivities and specificities over $87 \%$ and $91 \%$, respectively. Our results support the use of salivary Lf as an easily accessible, non-invasive and cost-effective biomarker for early $\mathrm{AD}$ diagnosis. Earlier and more reliable diagnoses for $\mathrm{AD}$ will have a direct impact on the design of future clinical trials. Finally, this study also propose that salivary Lf represents one of the main/first defence line against pathogens, hence low Lf levels in saliva may exacerbate AD risk.

\section{Introduction}

Alzheimer's disease (AD) is one of the most devastating neurodegenerative disorders representing a major public health concern with more than 30 million people affected worldwide. The cause of the disease is still unknown but the most accepted hypothesis states that amyloid- $\beta(\mathrm{A} \beta)$ accumulation in the brain could initially trigger the pathological cascade.

Accumulated evidence suggests that bacterial and viral infections may be implicated in AD pathogenesis [1-5]. In the cascade of events preceding $\mathrm{AD}$, oral and gastrointestinal microorganisms may play a role [6,7], and different types of microbes have shown to stimulate $\mathrm{A} \beta$ aggregation and deposition [8,9]. Therefore, it may exist an interplay between genetic and environmental risk factors including toxins and/or bacterial, viral and fungal pathogens in the sporadic form of late-onset $\mathrm{AD}$ reflecting its complex and multifactorial aetiology [10].

The question of whether oral infections could be considered as a risk factor for $\mathrm{AD}$ has generated considerable research in recent years. Antimicrobial proteins and peptides (APPs), also called host defence agents, are the primary effector molecules of innate immunity. A novel role for APPs has been proposed in AD pathology. The emerging role of microbes and innate immune pathways in $A D$ pathology also suggests that APPs may be considered for early therapeutic interventions in future clinical trials. Pathogen-targeting agents and brain infections markers are involved in amyloid aggregation, reinforcing the possible relationship between $\mathrm{AD}$ and brain infections [11,12].

Biomarkers reflecting innate immune system integrity could therefore be useful for both, accurate and early diagnosis, as well as disease prognosis. A promising biomarker candidate is lactoferrin (Lf), an iron-binding protein belonging to the transferrin family and expressed in all body fluids, particularly in exocrine fluids, tears or saliva [13]. Lf has a wide variety of physiological functions including, antioxidant activities, neuroprotective properties, regulation of the immune response, anti-inflammatory and anti-carcinogenic potential [14-18]. In addition, Lf has been previously detected in senile plaques, neurofibrillary tangles [19] and microglia from AD brains [20]. Since Lf is one of the major antimicrobial peptides in saliva, it further represents an important defensive element by inducing a broadspectrum of antimicrobial effects against bacteria, fungi, protozoa, viruses and yeasts [21]. The antimicrobial effects of Lf are conferred by its highly positive charged $\mathrm{N}$-terminal region [22]. These functions are maintained by its hydrolysis products, a number of Lf-derived peptides that by retaining the cationic $\mathrm{N}$-terminal region of the native protein also retain many of the Lf activities and in some cases, they can be even more potent than the parent protein [21,23].

We have previously shown decreased Lf levels in saliva samples from mild cognitive impairment $(\mathrm{MCI})$ and $\mathrm{AD}$ patients compared with normal elderly subjects [24]. In the present study, we have evaluated the diagnostic utility of salivary Lf in a well-characterised cohort of $\mathrm{AD}$ and frontotemporal dementia (FTD) patients, as well as in normal elderly subjects. Results have been lately validated in an independent cohort of MCI patients and healthy controls. In order to assess the salivary Lf specificity and its relationship with the pathophysiological process of $\mathrm{AD}$, only participants with known amyloidPositron-Emission Tomography (PET) status were included.

\section{Materials and methods}

\subsection{Human donors}

Two prospective, cross-sectional, multicenter studies were examined divided in two different cohorts. Study participants from cohort 1 were consecutively enrolled between 2014 and 2018 from the 12 de Octubre University Hospital Neurology Service in Madrid (Spain) and Pablo de Olavide University in Sevilla (Spain). Study participants from cohort 2 were consecutively enrolled between June 2017 and December 2018 as part of the Atherobrain - Heart to Head $(\mathrm{H} 2 \mathrm{H})$ project. Data from both cohorts were analysed in 2018.

All participants were classified using established diagnostic criteria into those with $\mathrm{MCI}$ or dementia including $\mathrm{AD}$ [25-27] and FTD [28], and those without clinical signs of cognitive impairment classified as healthy controls. Diagnosis was based on detailed clinical assessment, neuropsychological study, neuroimaging and amyloidPositron-Emission Tomography (PET) scan results. Global cognition was assessed using the Mini Mental State Examination (MMSE) [29]. Functional impairment was measured via the Clinical Dementia 
Rating (CDR) score [30]. All patients had to fulfil diagnosis criteria. Exclusion criteria were evidences of concomitant psychiatric, neurological or non-neurological medical conditions or medications that could affect cognition. Inclusion criteria for controls were age over 60 , MMSE score over 27, no history or clinical signs of neurological or psychiatric disease, and preservation of social and functional abilities.

116 participants composed cohort 1: 52 out of 116 were healthy asymptomatic subjects considered as controls, 21 out of 116 were diagnosed as $\mathrm{MCI}$ due to $\mathrm{AD}, 25$ out of 116 were $\mathrm{AD}$ dementia and 18 out of 116 were FTD. 142 participants composed cohort 2: 74 out of 142 were cognitively normal subjects, and 68 out of 142 patients were clinically diagnosed as $\mathrm{MCl}$. From the MCI group, 39 subjects were diagnosed as prodromal $\mathrm{AD}$ and the others as $\mathrm{MCI}$ not due to AD. Of all control participants 4 subjects from cohort 1 and 4 subjects from cohort 2 had a positive amyloid-PET $\left(\mathrm{PET}^{+}\right)$result. These participants were included in the demographic description to show the population heterogeneity, but not in the statistical analysis due to the small number of cases.

Approval of the study was obtained from the Research Ethics Committee of each entity, and all participants provided written consent to take part.

\subsection{Saliva samples}

Saliva samples were collected and processed from all subjects as described previously [24]. Briefly, an unstimulated saliva sample (about $0 \bullet 5-1 \mathrm{ml}$ ) was obtained by collection into a $2 \%$ sodium azide solution pre-coated sterile plastic tube. Samples were collected at a consistent time of day to avoid circadian effects and were kept on ice during and following collection. After collection was completed, saliva samples were pre-cleared by a low spin at $600 \times \mathrm{g}$ for $10 \mathrm{~min}$ at $4{ }^{\circ} \mathrm{C}$. $0 \cdot 5 \mathrm{ml}$ aliquots were stored at $-80^{\circ} \mathrm{C}$ after treatment with Protease Inhibitor Cocktail (Roche).

\subsection{DNA purification and APOE genotyping}

Genomic DNA was extracted from peripheral blood using QIAmp DNA Blood Mini Kit (Qiagen), according to the manufacturer instructions. Human APOE C112R and R158C polymorphisms were detected to identify the $A P O E \varepsilon 2, \varepsilon 3$ and $\varepsilon 4$ alleles, using LightCycler 480 II Instruments Kit (Roche Diagnostics) following manufacturer instructions.

\subsection{ELISA}

Levels of Lf in saliva samples were determined using the Lf human ELISA kit (ab200015, Abcam) according to manufacturer's instructions.

\subsection{Amyloid-PET scan}

Amyloid-PET scan was carried out in all participants. $\left[{ }^{18} \mathrm{~F}\right]-$ florbetapir (Amyvid, Eli Lilly \& Co. and Avid Radiopharmaceuticals Inc.), $\left[{ }^{18} \mathrm{~F}\right]$-florbetaben (Neuraceq, Pyramidal Imaging Limited), and $\left[{ }^{18} \mathrm{~F}\right]-$ flutemetamol (Vizamyl, GE Healthcare) PET scans were performed at the 12 de Octubre University Hospital, Pablo de Olavide University and the National Centre for Cardiovascular Research (CNIC), as previously described [31-33]. Images were generated 90-110 min after $\left[{ }^{18} \mathrm{~F}\right]$-florbetaben intravenous injection (mean dose, $300 \mathrm{MBq}$ ) or 90 min after $\left[{ }^{18} \mathrm{~F}\right]$-flutemetamol intravenous injection (mean dose, $185 \mathrm{MBq} ; 20 \mathrm{~min}$ acquisition) or $\left[{ }^{18} \mathrm{~F}\right]$-florbetapir intravenous injection (mean dose, $370 \mathrm{MBq} ; 20 \mathrm{~min}$ acquisition). Images were analysed with the Syngo PET $6 \bullet 7 \bullet 2$ (Siemens Healthcare) software and IntelliSpace Portal (Philips Healthcare) software. PET scans were analysed using standardised criteria [34].

\subsection{Statistical analysis}

We compared salivary Lf levels between the different diagnostic groups according to the amyloid-PET imaging biomarker profile. Numerical data are shown as mean \pm standard deviation (SD) and categorical data as a percentage. To compare demographic, clinical, and salivary Lf data within cohorts, we used one-way ANOVA followed by Bonferroni correction or the nonparametric Kruskal-Wallis rank test and non-parametric pairwise comparisons followed by Bonferroni correction, according to sample distribution. Student's $t$-test was used for single pairwise comparisons. Fisher's exact test was used to compare the distribution of categorical data across groups. Correlations between biomarker and subject's features were assessed using Spearman rank correlation. In addition, receiver operating characteristic (ROC) curve using binomial logistic regression analysis in the discovery cohort 1 and the validation cohort 2 were used to determine the diagnostic accuracy of salivary Lf to differentiate between diagnostic groups and amyloid-PET status. The optimal cutoff point was determined by Youden's J index $(J=$ sensitivity + specificity -1 ) by analysing the cohort 1 . Sensitivity, specificity and area under the curve (AUC) were calculated in all cases. Statistical significance was set at $p<0 \bullet 05$. Statistical analysis was performed using GraphPad Prism version $6 \bullet 00$ and STATA/IC $14 \bullet 2$ for Windows.

\section{Results}

\subsection{Demographics}

Demographic and clinical data of participants are shown in Table 1 (cohort 1 ) and Table 2 (cohort 2). In cohort 1 (Table $1, n=116$ subjects), 50 out of 116 participants were positive for amyloid-PET $\left(\mathrm{PET}^{+}\right)\left(43 \bullet 1 \%\right.$ prevalence) and 66 out of 116 were negative (PET ${ }^{-}$; $56 \%$ prevalence). From the $\mathrm{PET}^{+}$group, 21 out of 50 were clinically diagnosed with $\mathrm{MCI}$ due to $\mathrm{AD}$ (MCI-PET $; 42 \%$ prevalence), and 25 out of 50 were diagnosed with $\mathrm{AD}$ dementia $\left(\mathrm{AD}-\mathrm{PET}^{+} ; 50 \%\right.$ prevalence). Four controls showed a $\mathrm{PET}^{+}$status $\left(\right.$Control-PET ${ }^{+}$), representing the $7 \bullet 7 \%$ of all controls in cohort 1 . About the PET $^{-}$subjects, 18 out of 66 were clinically diagnosed with FTD (FTD-PET ${ }^{-} ; 27 \bullet 3 \%$ prevalence) and 48 out of 66 were found asymptomatic (Control-PET ${ }^{-}$; $72 \bullet 7 \%$ prevalence).

In the independent validation cohort (cohort 2; Table 2, $n=142$ subjects), 43 out of 142 participants were PET $^{+}(30 \bullet 3 \%$ prevalence) and 99 out of 142 were $\mathrm{PET}^{-} ; 73 \bullet 9 \%$ prevalence). All $\mathrm{PET}^{+}$subjects received the diagnosis of $\mathrm{MCI}$ due to $\mathrm{AD}$ except for 4 participants, which stayed cognitively healthy. This group represented the $5 \bullet 4 \%$ of all controls in cohort 2. From the PET ${ }^{-}$group, 29 out of 99 were diagnosed with $\mathrm{MCI}$ probably not due to $\mathrm{AD}\left(\mathrm{MCI}^{-\mathrm{PET}^{-}} ; \mathbf{2 9 \bullet 3 \%}\right.$ prevalence) and 70 out of 99 were found asymptomatic $(70 \bullet 7 \%$ prevalence).

No significant sex differences were found between groups. Mean age was statistically similar in all groups except for the FTD group from cohort 1, which was higher (Table 1). All patients showed lower MMSE scores than controls, specially $A D$ and FTD groups. As expected, APOE $\varepsilon 4$ genotype was significantly higher in $\mathrm{MCl}-\mathrm{PET}^{+}$ group and $\mathrm{AD}$ compared with asymptomatic subjects and FTD patients, according to previous publications [35-36].

In cohort 2, mean age was statistically similar in all groups. $\mathrm{MCI}$ patients showed lower MMSE scores than controls. Prevalence of $A P O E \& 4$ genotype was significantly higher in $\mathrm{MCI}-\mathrm{PET}^{+}$group and $\mathrm{AD}$ compared with asymptomatic subjects.

MCI-PET ${ }^{-}$group also showed a significantly higher prevalence of $A P O E \& 4$ genotype compared with the healthy control group.

\subsection{Salivary LF levels across diagnostic groups}

In cohort 1 , salivary Lf levels were significantly lower in MCI-PET $(3 \bullet 8 \pm 2 \mu \mathrm{g} / \mathrm{ml})$ and $\mathrm{AD}(3 \bullet 6 \pm 1 \bullet 5 \mu \mathrm{g} / \mathrm{ml})$ groups compared with 
Table 1

Demographic and clinical data of the participants in cohort 1.

\begin{tabular}{|c|c|c|c|c|c|c|}
\hline Characteristic & $\begin{array}{l}\text { Cohort } 1 \\
\text { Control-PET } \\
(n=48)\end{array}$ & $\begin{array}{l}\text { Control-PET } \\
(n=4)\end{array}$ & $\begin{array}{l}\text { MCI-PET }^{+} \\
(n=21)\end{array}$ & $\begin{array}{l}\text { AD-PET }^{+} \\
(n=25)\end{array}$ & $\begin{array}{l}\text { FTD-PET }^{-} \\
(n=18)\end{array}$ & $\begin{array}{l}\text { p-value } \\
\#\end{array}$ \\
\hline Age, mean (SD), y & $66 \bullet 9(5 \bullet 9)$ & $75 \bullet 9(3 \bullet 6)$ & $68 \bullet 8(7 \bullet 5)$ & $67 \cdot 2(9 \bullet 2)$ & $73 \bullet 8(5 \bullet 6)^{a, b}$ & $<0 \bullet 01$ \\
\hline Female sex, n (\%) & $33(68 \bullet 8)$ & $2(50 \bullet 0)$ & $8(38 \bullet 1)$ & $12(48 \bullet 0)$ & $11(61 \bullet 1)$ & ns \\
\hline Disease duration, mean (SD), y & - & - & $2 \bullet 8(1 \bullet 5)$ & $4 \bullet 0(1 \bullet 7)$ & $3 \bullet 7(1 \bullet 7)$ & ns \\
\hline MMSE score, mean (SD) & $29 \bullet 0(1 \bullet 1)$ & $28 \bullet 0(0 \bullet 8)$ & $25 \bullet 1(2 \bullet 3)^{d}$ & $19 \cdot 2(6 \bullet 0)^{\mathrm{c}, \mathrm{d}}$ & $20 \cdot 5(9 \cdot 2)^{\mathrm{d}}$ & $<0 \bullet 0001$ \\
\hline CDR, mean (SD) & 0 & 0 & $0 \bullet 5$ & $1 \bullet 3(0 \cdot 5)$ & $0 \bullet 9(0 \bullet 7)$ & NA \\
\hline APOE $\& 4$ carrier, No. (\%) & $6(17 \bullet 1)^{a, c}$ & - & $14(66 \bullet 7)$ & $12(48 \bullet 0)$ & $1(5 \bullet 6)^{\mathrm{c}, \mathrm{e}}$ & $<0 \bullet 0001$ \\
\hline Saliva Lf, $\mu \mathrm{g} / \mathrm{ml}$ (SD) & $7 \bullet 7(2 \bullet 4)$ & $9 \bullet 8(5 \bullet 4)$ & $3 \bullet 8(2 \bullet 0)^{\mathrm{d}, \mathrm{g}}$ & $3 \bullet 6(1 \bullet 5)^{\mathrm{d}, g}$ & $9 \bullet 7(2 \bullet 9)^{f}$ & $<0 \bullet 0001$ \\
\hline
\end{tabular}

Abbreviations: MCI, mild cognitive impairment; AD, Alzheimer's disease dementia; FTD, frontotemporal dementia; PET ${ }^{+}$, positive amyloid PET scan; PET $^{-}$, negative amyloid PET scan; MMSE, Mini-Mental State Examination; CDR, Clinical Dementia Rating; Lf, Lactoferrin; NA, not applicable; ns, non-significant. \#p value indicates statistical difference within the cohort1 [Bonferroni:

a $p<0 \bullet 05$ vs. AD-PET

b $p<0 \bullet 01$ vs. Control-PET ${ }^{-}$

c $p<0 \bullet 0001$ vs. MCI-PET ${ }^{+}$.

d $p<0 \bullet 0001$ vs. Control-PET ${ }^{-}$.

e $p<0 \bullet 01$ vs. AD-PET ${ }^{+}$.

f $p<0 \bullet 05$ vs. Control-PET ${ }^{-}$.

g $p<0 \bullet 0001$ vs. FTD-PET ${ }^{-}$].

Note: Control-PET ${ }^{+}$group is not included in statistical analysis.

cognitively normal elderly subjects $(7 \bullet 7 \pm 2 \bullet 4 \mu \mathrm{g} / \mathrm{ml} ; p<0 \bullet 0001$, Bonferroni; Fig. 1a), and FTD patients (mean $9 \bullet 7 \pm 2 \bullet 9 \mu \mathrm{g} / \mathrm{ml} ; p<$ $0 \bullet 0001$, Bonferroni; Fig. 1a). Lf levels in FTD group were slightly increased compared with controls $(p<0 \bullet 05$, Bonferroni) but the difference was much more relevant when comparing with $\mathrm{MCI}-\mathrm{PET}^{+}$ and AD-PET ${ }^{+}$groups. No significant differences in salivary Lf levels were found between $\mathrm{MCI}-\mathrm{PET}^{+}$and $\mathrm{AD}$ patients (Table 1, Fig. 1a). Regarding the control-PET ${ }^{+}$group, levels of Lf were inconsistent, showing values of $16 \bullet 0,12 \bullet 6,6 \bullet 0$ and $4 \bullet 6 \mu \mathrm{g} / \mathrm{ml}$.

In cohort 2, saliva Lf levels were significantly lower in $\mathrm{MCI}-\mathrm{PET}^{+}$ $(3 \bullet 5 \pm 2 \cdot 5 \mu \mathrm{g} / \mathrm{ml})$ group compared with healthy controls

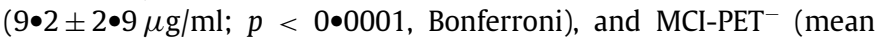
$7 \bullet 4 \pm 4 \bullet 6 \mu \mathrm{g} / \mathrm{ml} ; p<0 \bullet 0001$, Bonferroni; Table 2, Fig. 1b). No differences in salivary Lf levels were found between control and MCI-PET ${ }^{-}$ groups. Regarding the control-PET ${ }^{+}$group, levels of Lf tended to be down-regulated, and the 4 subjects showed values of $6 \bullet 5,4 \bullet 4,3 \bullet 8$ and $3 \bullet 7 \mu \mathrm{g} / \mathrm{ml}$.

Cohort 1 and cohort 2 combination ( $n=250$, excluding the 8 control-PET ${ }^{+}$subjects), resulted in 165 out of 250 PET $^{-}$and 85 out of 250 $\mathrm{PET}^{+}$subjects. Salivary Lf levels were significantly higher in the $\mathrm{PET}^{-}$ group $(8 \bullet 5 \pm 3 \cdot 2 \mu \mathrm{g} / \mathrm{ml})$ compared with the $\mathrm{PET}^{+}$group $(3 \bullet 6 \pm 2 \bullet 1 \mu \mathrm{g} / \mathrm{ml} ; p<0 \bullet 0001$, Student't; Fig. 1c). By excluding the control group, analysis also reported significant differences in salivary Lf levels between PET $^{-}$, covering FTD and some MCI patients $(8 \bullet 3 \pm 4 \bullet 2 \mu \mathrm{g} / \mathrm{ml})$, and PET $^{+}$patients $(p<0 \bullet 0001$, Student't; Fig. 1d).

\subsection{Correlations between salivary LF and demographic, clinical, and APOE genotype}

We then investigated correlations between salivary Lf concentrations and clinical and demographic data, including age, MMSE score, disease duration and CDR, in separated groups within cohorts and by combinination of all of them. We also assessed the effects of APOE $\& 4$ genotype in Lf levels. We found that higher salivary Lf levels were associated with higher MMSE scores $(r=0 \bullet 69 ; p<0 \bullet 01)$ and lower CDR scores $(r=-0 \bullet 59 ; p<0 \bullet 01)$ in the FTD group (Table 3$)$. No correlations were found either with MMSE or CDR in the other groups in cohort 1 and 2, nor between salivary Lf levels and age or disease duration in the combined or in the separated groups.

Table 2

Demographic and clinical data of the participants in cohort 2.

\begin{tabular}{llllll}
\hline Characteristic & $\begin{array}{l}\text { Cohort 2 } \\
\text { Control-PET } \\
(n=70)\end{array}$ & $\begin{array}{l}\text { Control-PET } \\
(n=4)\end{array}$ & $\begin{array}{l}\text { MCI-PET }^{-} \\
(n=29)\end{array}$ & $\begin{array}{l}\text { MCI-PET }^{+} \\
(n=39)\end{array}$ & $\begin{array}{l}\text { p-value } \\
\text { \# }\end{array}$ \\
\hline Age, mean (SD), y & $71 \bullet 1(5 \bullet 7)$ & $70 \bullet 3(4 \bullet 5)$ & $75 \bullet 3(5 \bullet 9)$ & $74 \bullet 4(5 \bullet 3)$ & ns \\
Female sex, n (\%) & $43(62 \bullet 3)$ & $2(50 \bullet 0)$ & $20(69 \bullet 0)$ & $26(66 \bullet 7)$ & $n s$ \\
Disease duration, mean (SD), y & - & - & $2 \bullet 6(1 \bullet 7)$ & $3 \bullet 3(1 \bullet 8)$ & ns \\
MMSE score, mean (SD) & $28 \bullet 6(1 \bullet 1)$ & $29 \bullet 5(0 \bullet 6)$ & $25 \bullet 1(2 \bullet 2)^{\mathrm{c}}$ & $24 \bullet 3(2 \bullet 1)^{\mathrm{c}}$ & $<0 \bullet 0001$ \\
CDR, mean (SD) & 0 & 0 & 0.5 & 0.5 & $\mathrm{NA}$ \\
APOE \&4 carrier, No. (\%) & $4(5 \bullet 7)$ & 0 & $7(24 \bullet 1)^{\mathrm{a}}$ & $12(30 \bullet 8)^{\mathrm{b}}$ & $<0 \bullet 001$ \\
Saliva Lf, $\mu \mathrm{gg} / \mathrm{ml}$ (SD) & $9 \bullet 2(2 \bullet 9)^{\mathrm{d}}$ & $4 \bullet 6(1 \bullet 3)$ & $7 \bullet 4(4 \bullet 6)^{\mathrm{d}}$ & $3 \bullet 5(2 \bullet 5)$ & $<0 \bullet 0001$ \\
& & & & &
\end{tabular}

Abbreviations: $\mathrm{MCI}$, mild cognitive impairment; $\mathrm{PET}^{+}$, positive amyloid PET scan; $\mathrm{PET}^{-}$, negative amyloid PET scan MMSE, Mini-Mental State Examination; CDR, Clinical Dementia Rating; Lf, Lactoferrin; NA, not applicable; ns, nonsignificant. $\# P$ value indicates statistical difference within the cohort 2. [Bonferroni:

a $p<0 \bullet 05$ vs. Control-PET ${ }^{-}$.

b $p<0 \bullet 01$ vs. Control-PET ${ }^{-}$.

c $p<0 \bullet 0001$ vs. Control-PET-

d $p<0 \bullet 0001$ vs. MCI-PET ${ }^{+}$.

Note: Control-PET ${ }^{+}$group is not included in statistical analysis. 


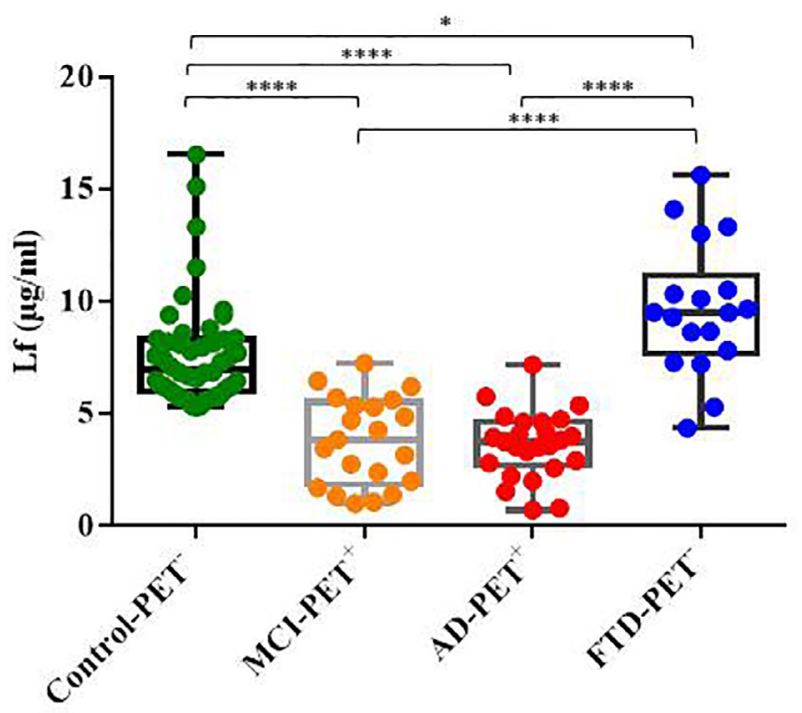

C

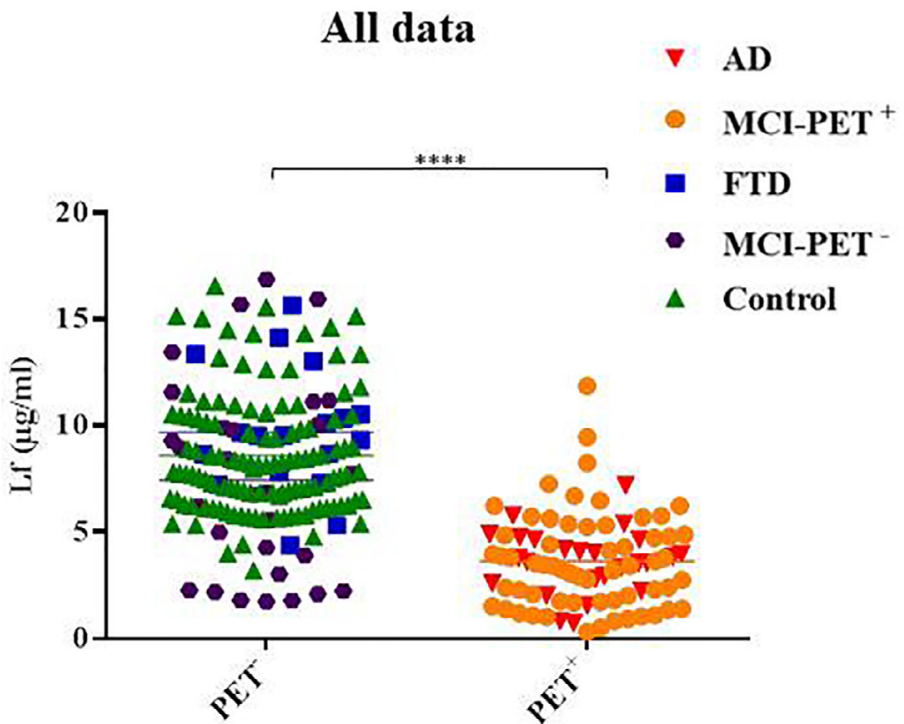

$\mathrm{b}$

Cohort 2

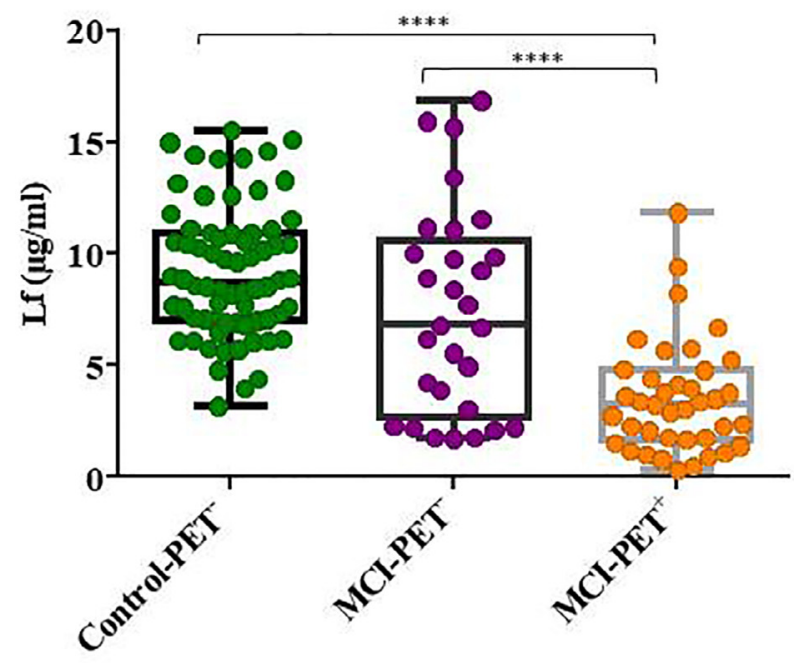

$\mathrm{d}$

Patients data

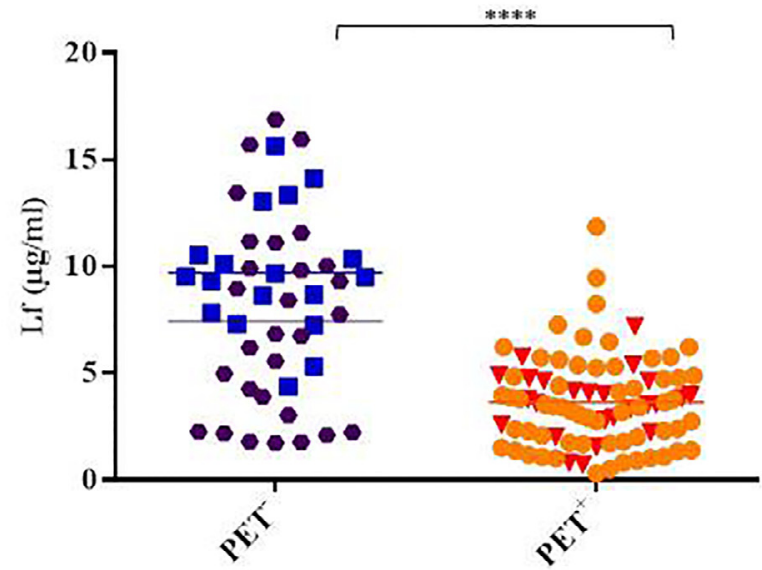

Fig. 1. Salivary Lf levels by clinical diagnosis and amyloid-PET biomarker profile. Box and whisker plots showing salivary Lf levels across diagnostic groups within (a) cohort 1 , and (b) cohort 2. Boxes represent the 25th, 50th and 75th data percentiles. Whiskers represent the lowest and highest data. Scatter plots showing salivary Lf levels in (c) all subjects grouped as negative $(n=165)$ and positive $(n=85)$ amyloid-PET biomarker profile (excluding the control-PET ${ }^{+}$subjects), and (d) in patients (excluding healthy asymptomatic controls) grouped as negative $(n=47)$ and positive $(n=85)$ amyloid-PET biomarker profile. Differences between groups were assessed using Kruskal-Wallis test or one-way ANOVA followed by Bonferroni and Student's $t$-test. ${ }^{*} p<0 \bullet 05 ;{ }^{* * * *} p<0 \bullet 0001$. Lf, lactoferrin; MCI, Mild cognitive impairment; AD, Alzheimer's disease dementia; FTD, frontotemporal dementia; PET $^{+}$, positive amyloid-PET scan; PET ${ }^{-}$, negative amyloid-PET scan.

According to $A P O E$ genotype, no differences were found between Lf levels in saliva in APOE $\varepsilon 4$ carriers compared with $A P O E \& 2$ and $\varepsilon 3$ carriers within the diagnostic groups, suggesting that the APOE $\& 4$ genotype is not related to salivary Lf levels.

\subsection{Diagnostic value for $L F$}

Lf results were analysed using logistic regression models in cohort 1 and the validation cohort 2 , excluding control PET $^{-}$from both cohorts. Using the Youden's index, we found that the optimal cut-off point to differentiate salivary Lf from MCI/AD-PET ${ }^{+}$patients and control-PET ${ }^{-}$group was $5 \bullet 63 \mu \mathrm{g} / \mathrm{ml}$ in cohort 1 . At this cut-off point, specificity and sensitivity were estimated in $91 \bullet 67 \%$ and $86 \bullet 96 \%$, respectively. The obtained area under the curve (AUC) was $0 \bullet 952$
(95\% CI, 0•911 - 0•992) (Table 4, Fig. 2a). Using the same cut-off point, the obtained sensitivity and specificity differentiating MCI/ADPET $^{+}$from FTD-PET ${ }^{-}$patients were $86 \bullet 96 \%$ and $88 \bullet 89 \%$, respectively.

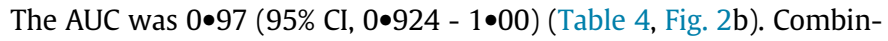
ing Lf levels from all subjects in cohort 1 grouped as $\mathrm{PET}^{-}$and $\mathrm{PET}^{+}$ and keeping the cut-off point of $5 \bullet 63 \mu \mathrm{g} / \mathrm{ml}$, we obtained $86 \bullet 96 \%$ sensitivity and $90 \bullet 91 \%$ specificity (Table 4 , Fig. 2 c).

In the validation cohort 2 analyses, the cut-off estimated from cohort 1 was replicated. The AUC to differentiate $\mathrm{MCI}-\mathrm{PET}^{+}$patients from control-PET ${ }^{-}$was $0 \bullet 93$ (95\% CI, $0 \bullet 876$ - 0•989), with $92 \bullet 86 \%$ specificity and $87 \bullet 05 \%$ sensitivity (Table 4 , Fig. 2 d). Both, the accuracy and specificity to differentiate $\mathrm{MCI}-\mathrm{PET}^{+}$from $\mathrm{MCI}-\mathrm{PET}^{-}$groups were lower (Table 4, Fig. 2e), due to the higher variability in the salivary Lf levels observed in the MCI-PET ${ }^{-}$group. That could be explained 
Table 3

Spearman rank correlations of saliva Lf levels with MMSE and CDR in the whole dataset and diagnostic groups.

\begin{tabular}{lllll}
\hline Correlation coefficient & \multicolumn{2}{c}{ Cohort 1} & & \\
& Whole dataset & Control & MCI/AD & FTD \\
\hline MMSE & $0 \bullet 42^{\mathrm{a}}$ & $0 \bullet 04$ & $-0 \bullet 03$ & $0 \bullet 69^{\mathrm{b}}$ \\
CDR & $-0 \bullet 49^{\mathrm{a}}$ & - & $-0 \bullet 19$ & $-0 \bullet 59^{\mathrm{b}}$ \\
Correlation coefficient & Cohort 2 & & & \\
MMSE & Whole dataset & Control & MCI-PET $^{+}$ & MCI-PET $^{-}$ \\
CDR & $0 \bullet 40^{\mathrm{a}}$ & $0 \bullet 20$ & $-0 \bullet 27$ & $-0 \bullet 04$ \\
\hline
\end{tabular}

Abbreviations: $\mathrm{MCI}$, mild cognitive impairment; AD, Alzheimer's disease dementia; FTD, frontotemporal dementia; PET+, positive amyloid PET scan; PET-, negative amyloid PET scan; MMSE, Mini-Mental State Examination; CDR, Clinical Dementia Rating.

[Spearman:

a $p<0 \bullet 0001$

b $p<0 \bullet 01]$.

Table 4

Sensibility and specificity of salivary Lf in cohort 1 and validation cohort 2 .

\begin{tabular}{|c|c|c|c|c|c|c|}
\hline & \multicolumn{3}{|l|}{$\begin{array}{l}\text { Cohort } 1 \\
(n=112)\end{array}$} & \multicolumn{3}{|c|}{$\begin{array}{l}\text { Validation cohort } 2 \\
(n=138)\end{array}$} \\
\hline & $\begin{array}{l}\text { MCI/AD-PET } \\
\text { vs. Control }\end{array}$ & $\begin{array}{l}\text { MCI/AD-PET } \\
\text { vs. FTD-PET } \\
\text { ' }\end{array}$ & $\begin{array}{l}\text { MCI/AD-PET } \\
\text { vs. }^{+} \text {PET }^{-}\end{array}$ & $\begin{array}{l}\text { MCI-PET }^{+} \\
\text {vs. Control }\end{array}$ & $\begin{array}{l}\text { MCI-PET }{ }^{+} \\
\text {vs. } \text { MCI-PET }^{-}\end{array}$ & $\begin{array}{l}\text { MCI-PET }^{+} \\
\text {vs. } \text { PET }^{-}\end{array}$ \\
\hline $\begin{array}{l}\text { AUC } \\
(95 \% \mathrm{CI})\end{array}$ & $\begin{array}{l}0 \bullet 95 \\
(0 \bullet 911,0 \bullet 992)\end{array}$ & $\begin{array}{l}0 \bullet 97 \\
(0 \bullet 924,1)\end{array}$ & $\begin{array}{l}0 \bullet 96 \\
(0 \bullet 922,0 \bullet 990)\end{array}$ & $\begin{array}{l}0 \bullet 93 \\
(0 \bullet 876,0 \bullet 989)\end{array}$ & $\begin{array}{l}0 \bullet 76 \\
(0 \bullet 637,0 \bullet 878)\end{array}$ & $\begin{array}{l}0 \bullet 88 \\
(0 \bullet 817,0 \bullet 945)\end{array}$ \\
\hline Sensitivity,\% & $86 \bullet 96$ & $86 \bullet 96$ & $86 \bullet 96$ & $87 \bullet 05$ & $84 \bullet 62$ & $82 \bullet 05$ \\
\hline Specificity,\% & $91 \bullet 67$ & $88 \bullet 89$ & $90 \bullet 91$ & $92 \bullet 86$ & $58 \bullet 62$ & $82 \bullet 83$ \\
\hline Accuracy,\% & $89 \cdot 36$ & $87 \cdot 50$ & $89 \bullet 29$ & $880 \bullet 99$ & $73 \bullet 53$ & $82 \bullet 61$ \\
\hline Cut-off, $\mu \mathrm{g} / \mathrm{ml}$ & $5 \bullet 63$ & $5 \bullet 63$ & $5 \bullet 63$ & $5 \bullet 63$ & $5 \bullet 63$ & $5 \bullet 63$ \\
\hline
\end{tabular}

Performance of salivary Lf analysed by receiver operating characteristic (ROC) curve, corresponding to the discovery data set (cohort 1 , left) and the validation data set (cohort 2, right). The optimal cut-off point to differentiate patients with AD from healthy controls from the cohort 1 was used to calculate sensibilities and specificities against the other groups analysed. This optimal cut-off point was determined by the Youden's index. Abbreviations: $\mathrm{MCI}$, mild cognitive impairment; AD, Alzheimer's disease dementia; FTD, frontotemporal dementia; PET $^{+}$, positive amyloid PET scan; PET $^{-}$, negative amyloid PET scan; AUC: area under the ROC curve; Lf, Lactoferrin.

because $\mathrm{MCI}$ patients with negative amyloid PET comprise a heterogeneous group with different and/or mixed non-amyloid aetiologies. Combining Lf levels from all subjects in cohort 2 grouped as PET $^{-}$and MCI-PET ${ }^{+}$and keeping the cut-off point of $5 \bullet 63 \mu \mathrm{g} / \mathrm{ml}$ from cohort 1 , we obtained $82.05 \%$ sensitivity and $82 \bullet 83 \%$ specificity with an AUC of $0 \bullet 88$ (95\% CI, $0 \bullet 817$ - 0•945) (Table 4, Fig. 2f). Overall, these results revealed that salivary $\mathrm{Lf}$ is able to differentiate between subjects with positive and negative cerebral amyloidosis with high accuracy.

\section{Discussion}

Here we show that reduced salivary Lf levels seem to be specific to $\mathrm{AD}$ as such observation is not extended to healthy elderly controls or FTD, as example of different dementia, neither to advanced age healthy controls. We demonstrate that reduced Lf levels are associated to positive amyloid PET result, one of the available pathophysiological validated $\mathrm{AD}$ biomarkers. These findings agree with our previously reported study in which reduced salivary Lf levels were found in amnesic MCI and AD patients [24].

Brain $\mathrm{A} \beta$ aggregation is thought to play a major role in $\mathrm{AD}$ aetiology, but the amyloid cascade hypothesis cannot explain the pathological process of AD by itself. In 2016, a hypothesis postulated that brain infections might play an initial role in amyloid plaque formation and the development of $\mathrm{AD}$ [37], proposing a potential novel role for APPs in AD pathophysiology [11]. These infections lead to persistent inflammatory stimuli altering the immune response [38]. Different lines of evidence suggest that AD-affected brains host virus, including herpes virus and hepatitis virus [1-5], and bacteria, including Chlamydia, Borrelia spirochetes, or Helicobacter Pylori [39]. Those bacterial and viral populations in the brain might induce $\mathrm{A} \beta$ aggregation, triggering the $A D$ pathophysiological process $[1-5,8,9]$. However, it remains unclear whether the entry of pathogens occurred at the onset of $A D$ or it may be the consequence of a leaky blood brain barrier (BBB) induced by chronic infections-derived inflammatory processes or, ultimately, if it is secondary to AD itself. It is important to recognise that infections can occur decades before evident signs of dementia. In agreement with this hypothesis, a number of risk factors, including chronic infections, obesity, diabetes, depression and stress among others, are known to contribute down-regulating the innate immune system and thus increasing the risk for infections. On this regard, is interesting to mention the recent work carried out by Ilievski and colleagues in which they have found a connection between oral infection and the development of AD-like pathology [40]. The authors orally administered Porphyromonas gingivalis (Pg) and/or its product gingipain to 8-month-old C57/BL6 mice for 22 weeks. Then, they found hippocampal and cortical neuropathology including $\mathrm{A} \beta$ plaques, neurofibrillary tangle formation, astrogliosis and microgliosis in the treated mice, but not in the control group [40]. More recently, Dominy and colleagues demonstrated the presence of Pg DNA and gingipain antigens in brains from $A D$ patients [41].

Oral homoeostasis is dependant upon saliva and its protein content. An alternative approach to understand the $\mathrm{AD}$ aetiopathogenesis has been recently reported: a potential microbial infection and innate immune origins for the disease [42]. This approach opened the way for a paradigm shift in studying a new "infection hypothesis," or perhaps more broadly, "innate immune system dysregulation hypothesis". It suggests the role of chronic infections in the 


\section{Cohort 1}

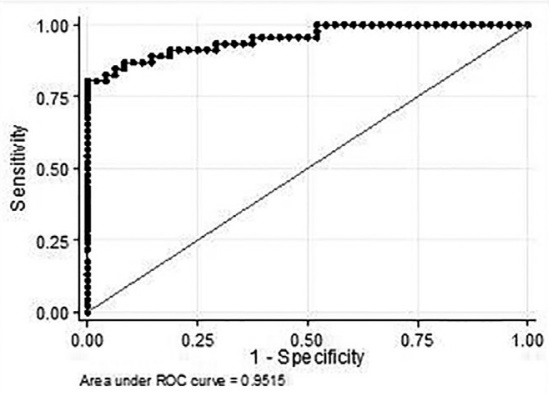

Are a under ROC Curve $=0.9515$ b

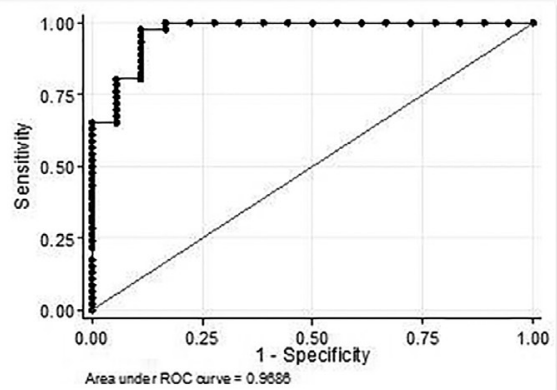

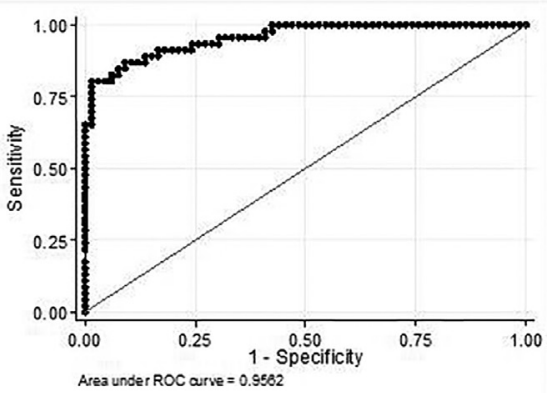

Validation cohort 2

e

MCI-PET $^{+}$vs. MCI-PET-

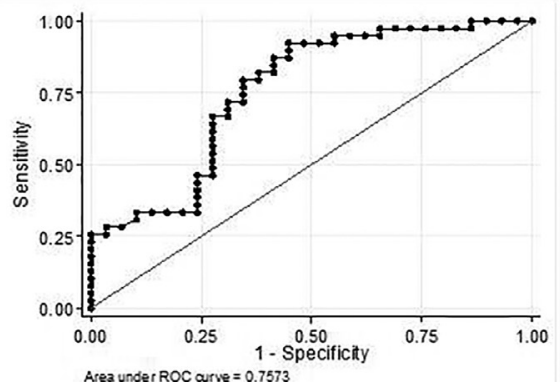

Area under ROC curve $=0.7573$ f MCI/PET $^{+}$vs. PET ${ }^{-}$

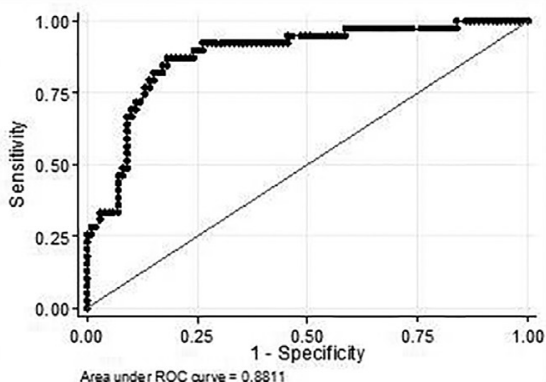

Area under ROC curve $=0.881$

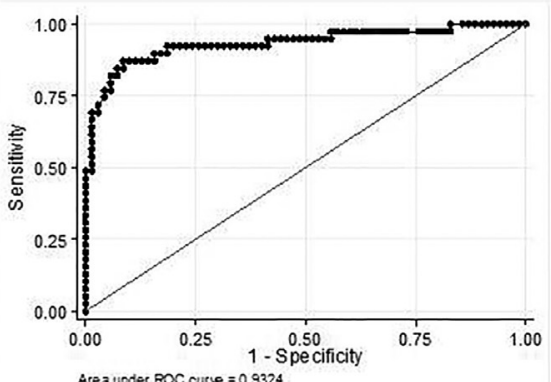

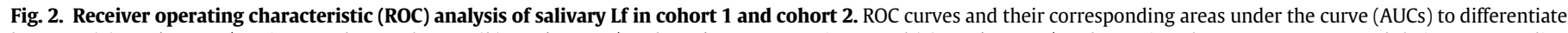

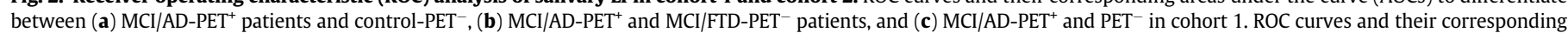

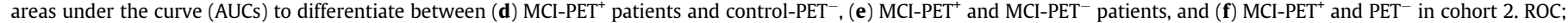

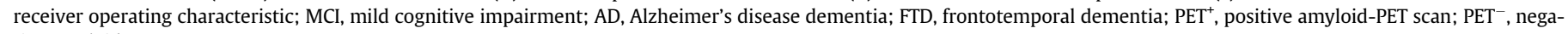
tive amyloid-PET scan.

development of $\mathrm{AD}$, as well as a potential deregulation of the human innate immune response to these infections, as a plausible route for new investigations of the aetiology and pathophysiology of $\mathrm{AD}$ [43]. Although $\mathrm{AD}$ is a complex disease and microbial infection may not be the sole cause, this new paradigm may provide novel targets for the prevention and treatment of this devastating disease.

The dissemination of oral microorganisms in the brain is controlled by APPs, as part of the innate immune system. In the last decade, several studies have explored the role of these APPs as potential biomarkers for AD [11]. In 2017, we showed that salivary Lf levels, one of the major antimicrobial proteins in saliva, discriminates between patients with $\mathrm{MCI}$ and $\mathrm{AD}$ and control subjects [24]. Although Lf cleavage generates antimicrobial peptides, sometimes with higher antimicrobial capacity, the protein itself has antimicrobial effects as these properties are conferred by its highly positive charged N-terminal domain and this domain is retained by its generated peptides. These differences come from the observation of Lfderived peptides exerted higher antibacterial capacity compared to native Lf. However, that was not the case of the antiviral capacity as several works demonstrated that mature protein has much more effect [21]. APPs are defensive agents constitutively expressed, but they can be modulated during inflammation or a microbial challenge, including chronic bacterial or viral infections. APPs have been studied for decades for their action against pathogens, and their immunostimulatory effects [23]. As part of the innate immune system, APPs are defensive peptides that enter the brain and efficiently target pathogens through synergistic pathways [11]. The normal production of APPs may be reduced because of a number of factors such as a weakened immune system or damaged defence cells. We then hypothesise that reduced levels of salivary Lf could reflect compromised immunity resulting in an enhanced risk of brain infections. Lf is known to be transferred from the sublingual mucosa to the brain [44]. In this context, favourable Lf effects on brain are expected, and they could be related to its antimicrobial capacity but also they may stimulate the non-amyloidogenic processing of APP and the $\alpha$-secretase catalytic activity and expression in a mouse model of AD [45].

Human Lf exerts multifunctional effects displaying extensive antimicrobial, anti-inflammatory and immunomodulatory activities. Lf may deprive microorganisms such as bacteria, yeasts and parasites binding and sequestering iron, which is essential for their growth [46]. Lf has different iron binding statuses: the iron-free (apo) form, the native form, and the iron-saturated (holo) form. It has been shown that both, the apo-Lf form as well as the holo-Lf form mediate agglutination of microorganisms indicating that Lf possess strong iron-binding independent bacteriolytic properties [47]. Moreover, previous studies also demonstrated that Lf showed antioxidant effects depending on its iron binding status [48]. Oxidative stress or damage such as protein oxidation, lipid oxidation, DNA oxidation, 
and glycoxidation is closely associated with the $\mathrm{AD}$ development [49]. The antioxidant effect of Lf could be explained as Lf restrains membrane lipid peroxidation by scavenging free iron radicals. These iron radicals are cytotoxic activators of lipid peroxidation and oxidative stress. It has been shown that Lf simultaneously enhances antioxidant activity by reducing ROS and enhancing SOD1 and reducing inflammatory markers in AD mice [45]. In a recent study with AD patients, Lf treatment showed significant improvements in antioxidant and anti-inflammatory markers in serum, and reduced $\mathrm{A} \beta 42$ and phosphorylated tau levels, as well as improved cognitive function [50]. Lf antioxidant activities have also been described in PD experimental models in which this protein was able to prevent oxidative stress and to upregulate the expression of antioxidant enzymes. Simultaneously, the expression of glial markers and proinflammatory cytokines were found reduced [51-52]. Therefore, a boosting effect of Lf may be potentially observed when this protein exerts its antioxidant properties through its iron scavenging abilities and this effect would potentiate the immune response [53].

In the present study, we report that salivary Lf levels are significantly reduced in AD patients but not in patients with other dementia such as FTD, suggesting a specific $A \beta$-related link. To our knowledge, this is the first study at examining the relationship between salivary Lf and brain $\mathrm{A} \beta$ plaques measured in vivo by amyloid-PET neuroimaging. Amyloid-PET has emerged as a tool for the diagnostic accuracy of prodromal $\mathrm{AD}$, as amyloid deposition occurs years before symptoms onset. $\mathrm{MCI}$ encompasses a heterogeneous syndrome with several aetiologies including neurodegenerative diseases, vascular, metabolic or psychiatric illness [27, 54]. Inaccuracy of clinicopathological correlation and common coexistence of different pathophysiological processes make difficult in most cases to establish a suitable diagnosis [27]. Furthermore, $\mathrm{MCl}$ without evidence of AD pathophysiology continues to be a mixed and frequently poorly defined group. In our study, Lf showed high variability levels in this group of patients, likely reflecting their biological diversity.

We show that the presence of a positive amyloid-PET signal, that indicates high amyloid plaque load, is highly associated with reduced levels of salivary Lf. These findings support the hypothesis that AD pathophysiology may be related to salivary levels of Lf and the innate immune response to brain infections. Innate immune pathways are commonly activated in other neurodegenerative disorders [55-58]. Therefore, it is remarkable that salivary Lf levels will not decrease in other dementia such as FTD. A possible explanation could be that the hypothalamic region, that controls body innate immunity, [59] is affected in $\mathrm{AD}$ [60-63], but not in FTD. In addition to amyloid plaques and neurofibrillary tangles, functional studies suggest that hypothalamic dysfunction is a common event in $\mathrm{AD}$, often early in the course of disease [61]. Although there are evidences indicating that certain hypothalamic regions are also affected in FTD, specifically those that correlate with abnormal eating behaviours [64], they are different to those affected in $\mathrm{AD}$. The apparently AD-specific salivary Lf reduction may thus not only be useful in the differential diagnosis but could also provide important insights into selective immune vulnerability in neurodegenerative diseases. The secretion of salivary proteins is controlled by cholinergic parasympathetic nerves that release acetylcholine, evoking the secretion of saliva by acinar cells in the salivary gland [65]. These parasympathetic nerves are connected with the hypothalamus [60-63]. We propose that early hypothalamic $\mathrm{A} \beta$ accumulation may disrupt hypothalamic function affecting salivary gland regulation that ultimately results in reduced salivary Lf secretion.

In 2011, the NIA-AA guidelines proposed a framework for the use of imaging and CSF biomarkers in the preclinical, $\mathrm{MCI}$ and dementia stages of $\mathrm{AD}[25,26,66,67]$. However, these current biomarkers used in $A D$ research are expensive or invasive, making difficult or impossible to include them in the routine clinical use in non-specialised health settings. Thus, the present research framework concludes the urgent need for the development of early diagnostic methods, incorporating new biomarkers that can accurately detect and diagnose AD. In recent years, there have been intensified efforts in searching minimum or non-invasive peripheral biomarkers in blood or saliva, for the early diagnosis of AD. Our present work show that salivary Lf levels are decreased in AD and are associated with amyloid-PET imaging profile even in prodromal disease, assuming the multifactorial and heterogeneous aetiology of dementia. The good correlation found in our study between amyloid-PET status and saliva Lf levels suggest that this inexpensive and easy-to-access measurement could be a potential candidate-screening tool in patients with cognitive impairment or suspicion of AD dementia.

In this study, we analysed Lf levels in cohort 1 where patients and control subjects were recruited from regions in Central and South of Spain. Second, the analysis was validated using the cohort 2 composed of donors recruited from Central Spanish region. Our present data demonstrates that the accuracy of salivary Lf as AD biomarker remains in these two separated geographic areas, suggesting that salivary Lf levels can be considered as reproducible biomarker and they may not be affected by other possible influences, including lifestyle and exposure to environmental factors. Other works showed on the contrary, that salivary Lf concentrations might be affected by circadian rhythms and physical activity [68-70], or environmental and lifestyle factors, including habits like smoking and medication-intake [71-73]. Therefore, it will be important to replicate these findings in larger-scale prospective and longitudinal studies with other different cohorts even with much more geographic separation. This will allow to accurately analysing the influence of other potential confounding variables.

In conclusion, to our knowledge, this is the first study that assesses the diagnostic performance and specificity of a salivarybased single biomarker to detect prodromal $A D$ and $A D$ dementia based on their amyloid-PET biomarker profile. Importantly, our findings have been replicated in an independent cross-sectional study able to replicate the diagnostic performance of saliva Lf concentration. Finally, this study also proposes that salivary Lf represents one of the main/first lines of defence against pathogens, and that low Lf levels in saliva may represent a reduced protection exacerbating the risk of AD.

\section{Acknowledgments}

We are grateful to the patients and donors without whom these works would not have been possible. We thank also Dr. Alberto Lleo and Dr. Pablo Martinez-Lage for their scientific discussion.

\section{Funding}

This study was supported by Dr. Carro grants from Instituto de Salud Carlos III (FIS15/00780, FIS18/00118), FEDER, Comunidad de Madrid (S2017/BMD-3700; NEUROMETAB-CM), and CIBERNED (PI2016/01). This study was also supported by research grants from the Spanish Ministry of Economy and Competitiveness (SAF201785310-R to Dr. Cantero, PSI2017-85311-P to Dr. Atienza); International Centre on ageing CENIE-POCTEP (0348_CIE_6_E to Dr. Atienza); and CIBERNED (CB06/05/1111 to Dr. Cantero). Dr. Bueno receives research funding from the Instituto de Salud Carlos III, Spain (PIE16/ 00021, PI17/01799). The H2H-Spain Study was supported in Spain by grant PIE16/00021 from Instituto Carlos III, Ministry of Science, Innovation and Universities, and additional funds from the Centro Nacional de Investigaciones Cardiovasculares (CNIC). The CNIC is supported by the Ministry of Economy, Industry and Competitiveness and the Pro CNIC Foundation, and is a Severo Ochoa Centre of Excellence (SEV-2015-0505). The funders had no role in the conceptualisation, study design, data collection analysis and preparation of this manuscript. 


\section{Declarations of Competing Interest}

Dr. Perry has served as a consultant for Neurtrope, Neurotez, Investiture. Dr. Bueno receives research funding from Astra-Zeneca, BMS, Janssen and Novartis; has received consulting fees from AstraZeneca, Bayer, BMS-Pfizer, Novartis; and speaking fees or support for attending scientific meetings from Astra-Zeneca, Bayer, BMS-Pfizer, Ferrer, Novartis, and MEDSCAPE-the heart.og. Dr. Carro and Dr. Orive are co-founders of GEROA Diagnostics. No other disclosures were reported.

\section{References}

1 Readhead B, Haure-Mirande JV, Funk CC, Richards MA, Shannon P, Haroutunian V et al. Multiscale analysis of independent Alzheimer's cohorts finds disruption of molecular, genetic, and clinical networks by human herpesvirus. Neuron 2018;99 (1):64-82.

2 Itzhaki RF. Herpes simplex virus type 1 and Alzheimer's disease: increasing evidence for a major role of the virus. Front Aging Neurosci 2014;6:202.

3 Mastroeni D, Nolz J, Sekar S, Delvaux E, Serrano G, Cuyugan L, et al. Laser-captured microglia in the Alzheimer's and Parkinson's brain reveal unique regional expression profiles and suggest a potential role for hepatitis B in the Alzheimer's brain. Neurobiol Aging 2018;63:12-21.

4 Lovheim H, Gilthorpe J, Adolfsson R, Nilsson LG, Elgh F. Reactivated herpes simplex infection increases the risk of Alzheimer's disease. Alzheimer's Dement J Alzheimer's Assoc 2015 Jun;11(6):593-9.

5 Lovheim H, Gilthorpe J, Johansson A, Eriksson S, Hallmans G, Elgh F. Herpes simplex infection and the risk of Alzheimer's disease: A nested case-control study. Alzheimer's Dement J Alzheimer's Assoc 2015 Jun;11(6):587-92.

6 Miklossy J. Alzheimer's disease - a neurospirochetosis. Analysis of the evidence following Koch's and Hill's criteria. J Neuroinflammation. 2011;8:90.

7 Hill JM, Clement C, Pogue AI, Bhattacharjee S, Zhao Y, Lukiw WJ. Pathogenic microbes, the microbiome, and Alzheimer's disease (AD). Front Aging Neurosci 2014;6:127.

8 Kumar DK, Eimer WA, Tanzi RE, Moir RD. Alzheimer's disease: the potential therapeutic role of the natural antibiotic amyloid-beta peptide. Neurodegener Dis Manag 2016 Oct;6(5):345-8.

9 Eimer WA, Vijaya Kumar DK, Navalpur Shanmugam NK, Rodriguez AS, Mitchell T, Washicosky KJ, et al. Alzheimer's disease-associated beta-amyloid is rapidly seeded by herpesviridae to protect against brain infection. Neuron 2018;99(1):56-63.

10 Itzhaki RF, Lin WR, Shang D, Wilcock GK, Faragher B, Jamieson GA. Herpes simplex virus type 1 in brain and risk of Alzheimer's disease. Lancet 1997 Jan 25;349 (9047):241-4

11 Welling MM, Nabuurs RJ, van der Weerd L. Potential role of antimicrobial peptides in the early onset of Alzheimer's disease. Alzheimer's Dement J Alzheimer's Assoc 2015 Jan; 11(1):51-7.

12 Kamer AR, Dasanayake AP, Craig RG, Glodzik-Sobanska L, Bry M, de Leon MJ. Alzheimer's disease and peripheral infections: the possible contribution from periodontal infections, model and hypothesis. J Alzheimers Dis 2008 May;13(4):43749.

13 Rosa L, Cutone A, Lepanto MS, Paesano R, Valenti P. Lactoferrin: A Natural Glycoprotein Involved in Iron and Inflammatory Homeostasis. Int J Mol Sci 2017 Sep $15 ; 18(9)$.

14 Valenti P, Antonini G. Lactoferrin: an important host defence against microbial and viral attack. Cell Mol Life Sci CMLS 2005;62(22):2576-87.

15 Puddu P, Latorre D, Carollo M, Catizone A, Ricci G, Valenti P, et al. Bovine lactoferrin counteracts Toll-like receptor mediated activation signals in antigen presenting cells. PLoS One 2011;6(7):e22504.

16 Rousseau E, Michel PP, Hirsch EC. The iron-binding protein lactoferrin protects vulnerable dopamine neurons from degeneration by preserving mitochondrial calcium homeostasis. Mol Pharmacol 2013 Dec;84(6):888-98.

17 Wang J, Ohno-Matsui K, Yoshida T, Kojima A, Shimada N, Nakahama K, et al. Altered function of factor I caused by amyloid beta: implication for pathogenesis of agerelated macular degeneration from Drusen. J Immunol 2008 Jul 1;181(1):712-20.

18 Yan D, Kc R, Chen D, Xiao G, Im HJ. Bovine lactoferricin-induced anti-inflammation is, in part, via up-regulation of interleukin-11 by secondary activation of STAT3 in human articular cartilage. J Biol Chem 2013 Nov 1;288(44):31655-69.

19 Kawamata T, Tooyama I, Yamada T, Walker DG, McGeer PL. Lactotransferrin immunocytochemistry in Alzheimer and normal human brain. Am J Pathol 1993 May;142(5):1574-85.

20 An L, Sato H, Konishi Y, Walker DG, Beach TG, Rogers J, et al. Expression and localization of lactotransferrin messenger RNA in the cortex of Alzheimer's disease. Neurosci Lett 2009 Mar 20;452(3):277-80.

21 Gifford JL, Hunter HN, Vogel HJ. Lactoferricin: a lactoferrin-derived peptide with antimicrobial, antiviral, antitumor and immunological properties. Cell Mol life Sci CMLS 2005 Nov;62(22):2588-98.

22 Orsi $\mathrm{N}$. The antimicrobial activity of lactoferrin: current status and perspectives. Biometals 2004 Jun; 17(3):189-96.

23 Xu G, Xiong W, Hu Q Zuo P, Shao B, Lan F, et al. Lactoferrin-derived peptides and Lactoferricin chimera inhibit virulence factor production and biofilm formation in Pseudomonas aeruginosa. J Appl Microbiol 2010 Oct;109(4):1311-8.
24 Carro E, Bartolome F, Bermejo-Pareja F, Villarejo-Galende A, Molina JA, Ortiz P, et al. Early diagnosis of mild cognitive impairment and Alzheimer's disease based on salivary lactoferrin. Alzheimer's Dement (Amsterdam, Netherlands) 2017;8:131-8.

25 Albert MS, DeKosky ST, Dickson D, Dubois B, Feldman HH, Fox NC, et al. The diagnosis of mild cognitive impairment due to Alzheimer's disease: recommendations from the National Institute on Aging-Alzheimer's Association workgroups on diagnostic guidelines for Alzheimer's disease. Alzheimer's Dement J Alzheimer's Assoc 2011 May; 7(3):270-9.

26 McKhann GM, Knopman DS, Chertkow H, Hyman BT, Jack Jr. CR, Kawas CH, et al. The diagnosis of dementia due to Alzheimer's disease: recommendations from the National Institute on Aging-Alzheimer's Association workgroups on diagnostic guidelines for Alzheimer's disease. Alzheimer's Dement J Alzheimer's Assoc 2011 May:7(3):263-9.

27 Winblad B, Palmer K, Kivipelto M, Jelic V, Fratiglioni L, Wahlund LO, et al. Mild cognitive impairment-beyond controversies, towards a consensus: report of the International Working Group on Mild Cognitive Impairment. J Intern Med 2004 Sep;256 (3):240-6.

28 Rascovsky K, Hodges JR, Knopman D, Mendez MF, Kramer JH, Neuhaus J, et al. Sensitivity of revised diagnostic criteria for the behavioural variant of frontotemporal dementia. Brain J Neurol 2011 Sep;134(Pt 9):2456-77.

29 Folstein MF, Folstein SE, McHugh PR. "Mini-mental state". A practical method for grading the cognitive state of patients for the clinician. J Psychiatr Res 1975 Nov;12 (3):189-98

30 Morris JC. The Clinical Dementia Rating (CDR): current version and scoring rules. Neurology 1993 Nov;43(11):2412-4.

31 Vandenberghe R, Van Laere K, Ivanoiu A, Salmon E, Bastin C, Triau E, et al. 18F-flutemetamol amyloid imaging in Alzheimer disease and mild cognitive impairment: a phase 2 trial. Ann Neurol 2010 Sep;68(3):319-29.

32 Clark CM, Pontecorvo MJ, Beach TG, Bedell BJ, Coleman RE, Doraiswamy PM, et al. Cerebral PET with florbetapir compared with neuropathology at autopsy for detection of neuritic amyloid-beta plaques: a prospective cohort study. Lancet Neurol 2012 Aug; 11(8):669-78.

33 Barthel H, Gertz HJ, Dresel S, Peters O, Bartenstein P, Buerger K, et al. Cerebral amyloid-beta PET with florbetaben (18F) in patients with Alzheimer's disease and healthy controls: a multicentre phase 2 diagnostic study. Lancet Neurol 2011 May; 10(5):424-35,

34 Dubois B, Feldman HH, Jacova C, Hampel H, Molinuevo JL, Blennow K, et al. Advancing research diagnostic criteria for Alzheimer's disease: the IWG-2 criteria. Lancet Neurol 2014 Jun;13(6):614-29.

35 Heffernan AL, Chidgey C, Peng P, Masters CL, Roberts BR. The Neurobiology and Age-Related Prevalence of the epsilon4 Allele of Apolipoprotein E in Alzheimer's Disease Cohorts. J Mol Neurosci 2016 Nov;60(3):316-24.

36 Verpillat P, Camuzat A, Hannequin D, Thomas-Anterion C, Puel M, Belliard S, et al. Apolipoprotein E gene in frontotemporal dementia: an association study and meta-analysis. Eur J Hum Genet EJHG 2002 Jul;10(7):399-405.

37 Itzhaki RF, Lathe R, Balin BJ, Ball MJ, Bearer EL, Braak H, et al. Microbes and Alzheimer's Disease. J Alzheimer's Dis JAD 2016;51(4):979-84.

38 Krstic D, Madhusudan A, Doehner J, Vogel P, Notter T, Imhof C, et al. Systemic immune challenges trigger and drive Alzheimer-like neuropathology in mice. J Neuroinflammation 2012 Jul 2;9:151.

39 Itzhaki RF, Wozniak MA, Appelt DM, Balin BJ. Infiltration of the brain by pathogens causes Alzheimer's disease. Neurobiol Aging 2004:25(5):619-27.

40 Ilievski V, Zuchowska PK, Green SJ, Toth PT, Ragozzino ME, Le K, et al. Chronic oral application of a periodontal pathogen results in brain inflammation, neurodegeneration and amyloid beta production in wild type mice. PLoS One 2018;13(10): e0204941.

41 Dominy SS, Lynch C, Ermini F, Benedyk M, Marczyk A, Konradi A, et al. Porphyromonas gingivalis in Alzheimer's disease brains: evidence for disease causation and treatment with small-molecule inhibitors. Sci Adv 2019 Jan;5(1):eaau3333.

42 Fulop T, Itzhaki RF, Balin BJ, Miklossy J, Barron AE. Role of Microbes in the Development of Alzheimer's Disease: State of the Art - An International Symposium Presented at the 2017 IAGG Congress in San Francisco. Front Genet 2018;9:362.

43 Bermejo-Pareja F, del Ser T, Valentí M, de la Fuente M, Bartolome F, Carro E. Salivary lactoferrin as biomarker for Alzheimer's disease: Brain-immunity interactions. Alzheimer's Dement J Alzheimer's Assoc 2020:1-8 doi.org/10.1002/alz.12107.

44 Hayashi T, To M, Saruta J, Sato C, Yamamoto Y, Kondo Y, et al. Salivary lactoferrin is transferred into the brain via the sublingual route. Biosci Biotechnol Biochem 2017 Jul;81(7):1300-4.

45 Guo C, Yang ZH, Zhang S, Chai R, Xue H, Zhang YH, et al. Intranasal Lactoferrin Enhances alpha-Secretase-Dependent Amyloid Precursor Protein Processing via the ERK1/2-CREB and HIF-1alpha Pathways in an Alzheimer's Disease Mouse Model. Neuropsychopharmacol Off Publ Am Coll Neuropsychopharmacol 2017 Dec;42(13):2504-15.

46 Baker HM, Baker EN. Lactoferrin and iron: structural and dynamic aspects of binding and release. Biometals 2004 Jun;17(3):209-16.

47 Arslan SY, Leung KP, Wu CD. The effect of lactoferrin on oral bacterial attachment. Oral Microbiol Immunol 2009 Oct;24(5):411-6.

48 Zakharova ET, Sokolov AV, Pavlichenko NN, Kostevich VA, Abdurasulova IN, Chechushkov AV, et al. Erythropoietin and Nrf2: key factors in the neuroprotection provided by apo-lactoferrin. Biometals 2018 Jun;31(3):425-43.

49 Nunomura A, Castellani RJ, Zhu X, Moreira PI, Perry G, Smith MA. Involvement of oxidative stress in Alzheimer disease. J Neuropathol Exp Neurol 2006 Jul;65 (7):631-41.

50 Mohamed WA, Salama RM, Schaalan MF. A pilot study on the effect of lactoferrin on Alzheimer's disease pathological sequelae: Impact of the p-Akt/PTEN pathway. Biomed Pharmacother 2019;111:714-23. 
51 Wang J, Bi M, Liu H, Song N, Xie J. The protective effect of lactoferrin on ventral mesencephalon neurons against MPP + is not connected with its iron binding ability. Sci Rep 2015 Jun 2;5:10729.

52 Xu SF, Zhang YH, Wang S, Pang ZQ, Fan YG, Li JY, et al. Lactoferrin ameliorates dopaminergic neurodegeneration and motor deficits in MPTP-treated mice. Redox Biol 2019 Feb;21:101090.

53 Mulder AM, Connellan PA, Oliver CJ, Morris CA, Stevenson LM. Bovine lactoferrin supplementation supports immune and antioxidant status in healthy human males. Nutr Res 2008 Sep;28(9):583-9.

54 Dugger BN, Davis K, Malek-Ahmadi M, Hentz JG, Sandhu S, Beach TG, et al. Neuropathological comparisons of amnestic and nonamnestic mild cognitive impairment. BMC Neurol 2015 Aug 20;15:146.

55 Busse M, Michler E, von Hoff F, Dobrowolny H, Hartig R, Frodl T, et al. Alterations in the peripheral immune system in Dementia. J Alzheimers Dis 2017;58(4):1303-13.

56 Pawlowski M, Lueg G, Gross CC, Johnen A, Kramer J, Weckesser M, et al. Relevance of raised cerebrospinal fluid monocyte levels in patients with frontotemporal dementia. Neurobiol Aging 2018 Feb;62:45-52.

57 Heneka MT, Golenbock DT, Latz E. Innate immunity in Alzheimer's disease. Nat Immunol 2015 Mar;16(3):229-36.

58 Heneka MT, Kummer MP, Latz E. Innate immune activation in neurodegenerative disease. Nat Rev Immunol 2014 Jul;14(7):463-77.

59 Haas HS, Schauenstein K. Neuroimmunomodulation via limbic structures-the neuroanatomy of psychoimmunology. Prog Neurobiol 1997 Feb;51(2):195-222.

60 Baloyannis SJ, Mavroudis I, Mitilineos D, Baloyannis IS, Costa VG. The hypothalamus in Alzheimer's disease: a Golgi and electron microscope study. Am J Alzheimer's Dis Dement 2015 Aug;30(5):478-87.

61 Ishii M, Iadecola C. Metabolic and non-cognitive manifestations of Alzheimer's disease: the hypothalamus as both culprit and target of pathology. Cell Metab 2015 Nov 3;22(5):761-76.

62 Goldstein DS, Kopin IJ. Homeostatic systems, biocybernetics, and autonomic neuroscience. Auton Neurosci Basic Clin 2017 Dec;208:15-28.
63 Zheng H, Zhou Q, Du Y, Li C, Xu P, Lin L, et al. The hypothalamus as the primary brain region of metabolic abnormalities in APP/PS1 transgenic mouse model of Alzheimer's disease. Biochim Biophys Mol Basis Dis 2018 Jan;1864(1):263-73.

64 Piguet O, Petersen A, Yin Ka Lam B, Gabery S, Murphy K, Hodges JR, et al. Eating and hypothalamus changes in behavioral-variant frontotemporal dementia. Ann Neurol 2011 Feb;69(2):312-9.

65 Proctor GB, Carpenter GH. Regulation of salivary gland function by autonomic nerves. Auton Neurosci Basic Clin 2007 Apr 30;133(1):3-18.

66 Jack Jr. CR, Bennett DA, Blennow K, Carrillo MC, Dunn B, Haeberlein SB, et al. NIAAA research framework: toward a biological definition of Alzheimer's disease. Alzheimer's Dement J Alzheimer's Assoc 2018 Apr;14(4):535-62.

67 Jack Jr. CR, Albert MS, Knopman DS, McKhann GM, Sperling RA, Carrillo MC, et al. Introduction to the recommendations from the National Institute on Aging-Alzheimer's Association workgroups on diagnostic guidelines for Alzheimer's disease. Alzheimer's Dement J Alzheimer's Assoc 2011 May;7(3):257-62.

68 Gillum TL, Kuennen MR, Castillo MN, Williams NL, Jordan-Patterson AT. Exercise, but not acute sleep loss, increases salivary antimicrobial protein secretion. Strength Cond Res 2015 May;29(5):1359-66.

69 Killer SC, Svendsen IS, Gleeson M. The influence of hydration status during prolonged endurance exercise on salivary antimicrobial proteins. Eur J Appl Physiol 2015 Sep;115(9):1887-95.

70 Svendsen IS, Hem E, Gleeson M. Effect of acute exercise and hypoxia on markers of systemic and mucosal immunity. Eur J Appl Physiol 2016 Jun;116(6):1219-29.

71 Berlutti F, Pantanella F, Natalizi T, Frioni A, Paesano R, Polimeni A, et al. Antiviral properties of lactoferrin-a natural immunity molecule. Molecules 2011 Aug 16;16 (8):6992-7018.

72 Nishida N, Yamamoto Y, Tanaka M, Kataoka K, Kuboniwa M, Nakayama K, et al. Association between involuntary smoking and salivary markers related to periodontitis: a 2-year longitudinal study. J Periodontol 2008 Dec;79(12):2233-40.

73 Persson L, Bergström J, Ito H, Gustafsson A. Tobacco smoking and neutrophil activity in patients with periodontal disease. J Periodontol 2001 Jan;72(1):90-5. 